\title{
A Study of College Basketball LAMS Teaching Model Centered on Learning Activities
}

\author{
https://doi.org/10.3991/ijet.v13i08.9052 \\ Feng Sheng $\left({ }^{\varpi}\right)$, Shaozeng Sheng \\ Qufu Normal University, Qufu, China \\ 3352165615 @qq.com
}

\begin{abstract}
Traditional basketball teaching has some problems, including the duplication of contents, outdated methods, disconnection between theories and practice, and lack of discussion on the use of computer technology and Internet technology to optimize the existing teaching mode. Based on the theoretical basis of "learning activities as the center", a LAMS (Learning Activity Management System) teaching mode was proposed in this study for the course of "College Basketball". It consists of three parts: the design module, the learning module, and the monitoring module. The LAMS-based college basketball teaching mode mainly includes learning activities, and learning resources and tools. Learning activities mainly involve teaching objectives, creation of learning activities, collection of information concerning learning activities, information analysis and improvement of activities. Meanwhile, learning resources and tools were set for the smooth progress of learning activities. After the teaching mode was constructed, it was applied in practical teaching at Shandong Normal University in Shandong Province, China. The teaching results show that compared to the traditional teaching mode, the LAMS teaching mode centered on learning activities can significantly improve the effect of teaching College Basketball.
\end{abstract}

Keywords-LAMS Teaching Model, Learning Activities, College Basketball

\section{Introduction}

With rapid development of computer and internet technologies, people's lifestyle, working modes, and learning styles have changed dramatically. Thus, optimizing existing teaching modes employing computer and internet technologies have become a focus of research in education. The teaching theory of "learning activities as the center" applied by LAMS has been studied widely and is considered the representative of new teaching design orientation [1]. LAMS teaching mode is an electronic learning system used for creating, managing, and providing online cooperation learning activities. It presents different activity construction techniques in a complete and effective mode. Through the built-in functions of this system, such as sharing working area, wiki editing, asking and answering, multiple choices, voting activity, and other 
communication tools (forum), group members can design, manage, and deliver learning activity sequence while exchanging their opinions [2].

College basketball teaching as one of the important parts of physical education and plays an important role in implementing quality-oriented education and cultivating students' abilities. College basketball teaching and training cannot be separated from teacher's explanation and demonstration. In traditional basketball teaching, vivid, visual, and accurate display of movements are lacking. Moreover, demonstration movements are often inaccurate because of the limitation of physical quality decrease. Picture presentations lack a time concept, and basketball mechanics are not shown visually. Teaching videos just make the completed movements reappear, or imitate others action or analyze the errors. There is lack of correct and difficult acting objectives. Moreover, video-based teaching is not visual, vivid, or coherent, compared with human motion acting. Thus, these shortcomings to certain degree affects students' learning initiative, easily leads to learning burnout and reduces learning effect and teaching effect. With the development of internet technology, LAMS as a new multimedia teaching method has been integrated in the educational field and is changing the development course of education to a certain extent. LAMS can be used for designing learning activity sequence and facilitate learning problem solving skill in an online environment. Medical students can concentrate on the evidence in medical literature. Researchers of the Medical College in the University of Sydney have proven the effectiveness of this teaching mode [3]. In 2015, the University of Hong Kong and Hong Kong Polytechnic University developed a new LAMS-based online teaching mode through a cross-major team learning project (IPTBL). In this mode, a teacher can control the release of teaching materials in different TBL steps. The mode can offer asynchronous teaching management for every student or learning team, increases the flexibility of the learning process, and enables the monitoring of teaching progress [4]. In this study, a LAMS teaching mode was applied in college basketball teaching. And, the case was combined to describe the specific implementation method.

\section{State of the art}

In the past ten years, the growth of online teaching method has attracted considerable attention. The Internet offers convenience and flexibility, providing learners convenient ways for accessing learning guidance. Many science and engineering disciplines have started to combine online teaching modes and have gained good effects.

In terms of PE, Peng [5] proposed "game spirit" is the real intention of PE. Imbuing game spirit through PE is necessary because this approach enable students to gradually form positive sports value and life attitude, which is the due value orientation of PE and the fundamental driving force to break down the development bottleneck of PE. Sun [6] considered that current college PE reform basically focuses on college PE itself, and the reform scope is basically limited to PE course content selection, organization, arrangement, and teaching form change. The college PE reform problems fail to be analyzed and solved from the social, economic, cultural, and edu- 
cational development perspectives. Some scholars indicated that online course of sports colleges is an information-based teaching resource that can be shared without limits. It makes educational resources break through space limit and radiate to the whole society, and provides play to multifunctional education advantages [4].

Researchers mainly focused on the functions of PE. For example, SEAN HEALY proposed that online teaching is an effective environment for special PE. This study provides greater flexibility for learners and teachers, and proposes the design and implementation principles which must be followed to ensure effectiveness of online courses [5]. Takahiro Sato suggested that online course teachers should change the teaching style to problem solving learning mode for the improvement of teacher's participation in online learning [1].

Current research on PE teaching mostly focus on the significance and development of PE. The implementation of PE in detail and the improvement of current PE teaching mode through computer and network technologies are rarely investigated. These researches fail to arouse the attention of relevant scholars.

This study focuses on the application of online teaching in PE teaching and indicates the positive significance of online PE teaching, namely effectively expand campus learning and social popularity of sports knowledge. In particular, this study focuses on teaching mode problem of online teaching. To try a new teaching method for technical courses, we innovatively applied the LAMS teaching mode in online teaching of college basketball.

\section{College basketball LAMS teaching mode based on learning activities}

The current situation of PE teaching was analyzed by referring to relevant literature about PE teaching. The plights faced by PE teaching were summarized by consolidating the problems encountered in college PE teaching. Theoretical knowledge is not highly valued, outdoor courses are affected by the weather and it influencing the final effect; teacher's professional knowledge cannot be well exerted; due to the limit of class size, students cannot learn more interesting courses. To solve these problems, innovation progress of domestic and overseas PE teaching method was analyzed. In combination of the rise of online courses under internet environment, we combined online teaching and advanced LAMS teaching mode and took College Basketball for example to conduct the teaching experiment, explore the development direction of college PE courses, generate a positive social influence, improve the social popularity of PE course, and further promote national fitness.

\subsection{Functional modules of LAMS teaching mode}

LAMS teaching mode mainly includes three functional modules, namely, design module, learning module, and monitoring module.

Design module: LAMS teaching mode provides an environment that is conducive to visualization. In the design of a teaching process, the activity tools needed can be 
dragged and then connected to the activities with a connecting line. This process form a learning activity sequence of the LAMS teaching mode. Such visualized convenient operation greatly reduces teacher's obstacle in software use.

Learning module: the learning module of LAMS teaching mode provides the teaching content created by creators for learners logging in corresponding courses of LAMS teaching mode, that is, learning activity sequence.

Monitoring module: the monitoring module of LAMS teaching mode can be used for checking the learning progress of every learner in the activity sequence of the LAMS teaching mode. The teacher can understand learners' obstacles in a visual way and adjust relevant activities or adopt other measures after the summarization.

\subsection{Application of LAMS in College Basketball teaching}

In this study, online teaching was achieved through the construction of the LAMS teaching mode for college basketball. Learning activities were designed by the functions of LAMS teaching mode. Progress control, community synergy, and other functions were utilized for collecting feedback information and completing the main process of experiment. In combination of PE teaching process, the experimental course College Basketball was divided into learning activity design, learning progress control, learning material preparation, learning information collection, course discussion, and targeted improvement. Learning activity design is in the central position in the course, and it is the output of long-term teaching experience. The LAMS teaching mode system was combined for the continuous optimization of feedback in an information-based manner. LAMS tools were used for the management of learning progress, analysis of learning effect, and optimization of learning activity design after the summarization.

\subsection{Teaching mode design centered on learning activities}

Concept of teaching mode. The teaching mode is a structured or ordered model or normal form used for guiding teaching activity implementation. In this study, the teaching mode centered on learning activities was evaluated. The teaching mode was defined as follows: relatively stable and ordered learning activity sequence and structure form was constructed on the basis of educational thought. It is both a theory and a program with strong enforceability. The composition of a complete teaching mode is shown in Fig.1.

\begin{tabular}{|c|c|c|c|}
\hline $\begin{array}{l}\text { The auxiliary link is } \\
\text { about } 1 \text { minutes }\end{array}$ & $\begin{array}{l}\text { learning about } 15 \\
\text { minutes }\end{array}$ & $\begin{array}{l}\text { teaching for about } 10 \\
\text { minutes }\end{array}$ & $\begin{array}{c}\text { class training for } 20 \\
\text { minutes }\end{array}$ \\
\hline $\begin{array}{l}\text { Put forward a topic } \\
\text { Show the target } \\
\text { Guided by self-study }\end{array}$ & $\begin{array}{c}\text { first watch videos } \\
\text { check exercises or } \\
\text { questions }\end{array}$ & $\begin{array}{l}\text { correct students' } \\
\text { answers } \\
\text { discuss with teachers } \\
\text { and students }\end{array}$ & $\begin{array}{l}\text { complete training } \\
\text { tasks }\end{array}$ \\
\hline
\end{tabular}

Fig. 1. Composition of teaching mode 
Activity theory in teaching process. Atcitty is the basic unit in the activity theory. In the teaching process, activity system is composed of student, teaching objective, co-learners, teaching environment, teaching rule, and teaching task. Their relations are shown in Fig.2.

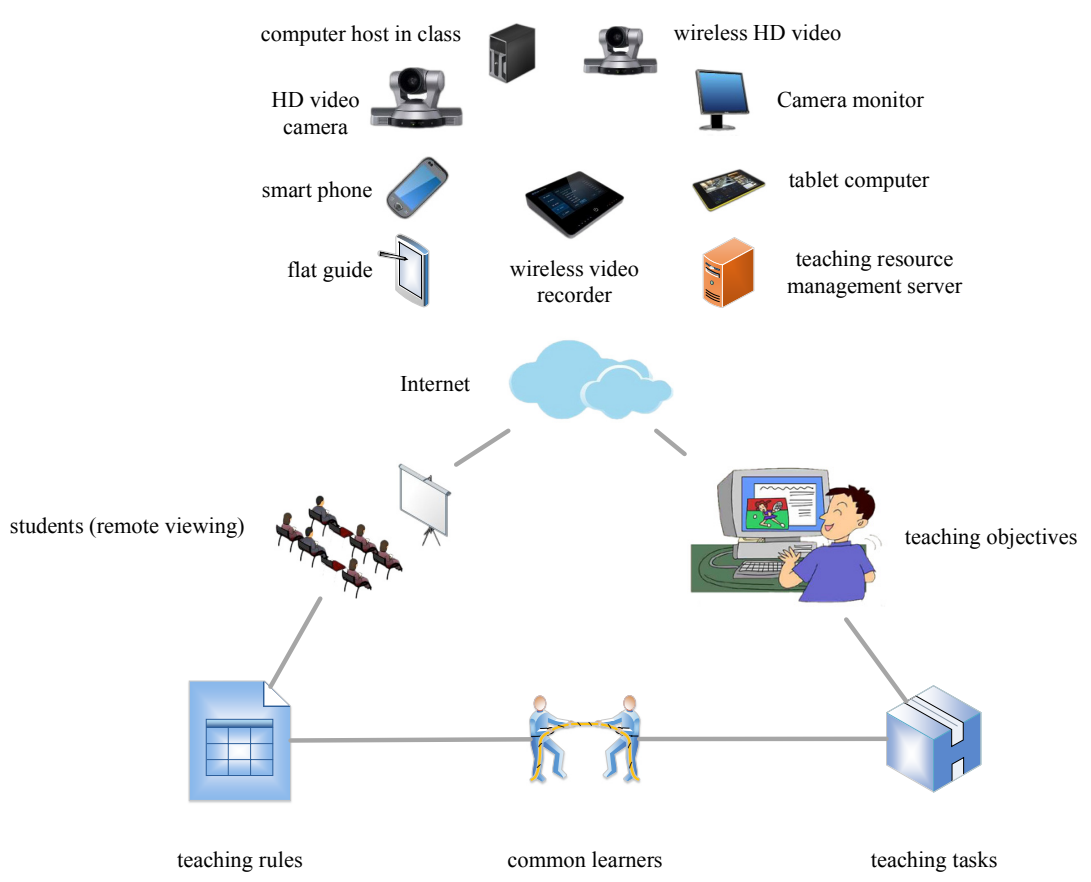

Fig. 2. Diagram of teaching activity system

Student: Student is the subject of teaching activities and also the executor of teaching activities. In the LAMS teaching mode, students' cognitive level can be analyzed according to their learning progress and completion for the adjustment of learning activity design.

Teaching objective: Also called learning objective, teaching objective is changed by students through certain activities. The setting of learning objective has strong subjectivity, but teaching objectives have objective requirements. Rational setting and timely adjustment of learning objective are the precondition for teaching activities to reach the teaching effect. In the LAMS teaching mode, the teaching objective can be rationally evaluated through the collection and completion of teaching objectives and other data.

Co-learners: All teaching activity participants except students are called colearners. Co-learners can offer guidance, participate in activities, and provide activity resources for students in the teaching activity. Co-learners influence students continuously in the entire activity, so they play an important role.

Teaching environment: The teaching environment includes hardware and software facilities used in the teaching process. Computers and teaching materials are the 
hardware environment. Favorable learning experience and interesting learning activity design belong to the software environment. A good environment facilitates the completion of the teaching objective.

Teaching rule: The teaching rule make the subjects and co-learners act their roles well and complete their duties in the teaching process

Teaching task: The diverse members in the teaching activity should plan the task well. In particular, the teacher should complete knowledge instruction, course arrangement staff should design teaching materials, data analysts should offer teaching activity design suggestions, students should learn, and technical staff should offer technical support.

Concept of teaching design theory. The teaching design theory is a technology theory with natural diversity. Activity-based teaching design theory indicates that three design objects are available for teaching design: learning activity, learning environment, and knowledge transfer, where learning activity design is the core design content of teaching design. Meanwhile, the three design objectives form the hierarchical relation (see Fig.3).

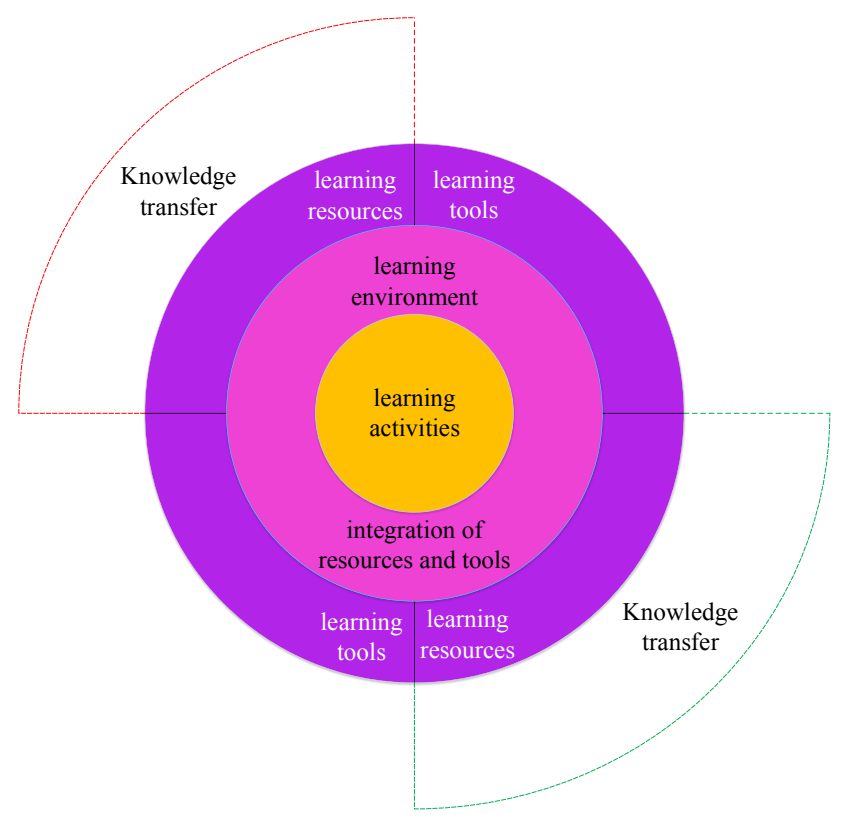

Fig. 3. Objects of teaching design centered on learning activities and their relations

Teaching program design. Teaching program is the program structure which develops according to the time order of teaching activities. It specifies the activities and goals that teachers and students should complete in each link. Under the LAMS teaching mode, we designed the following teaching program centered on teaching activities (Fig.4). 


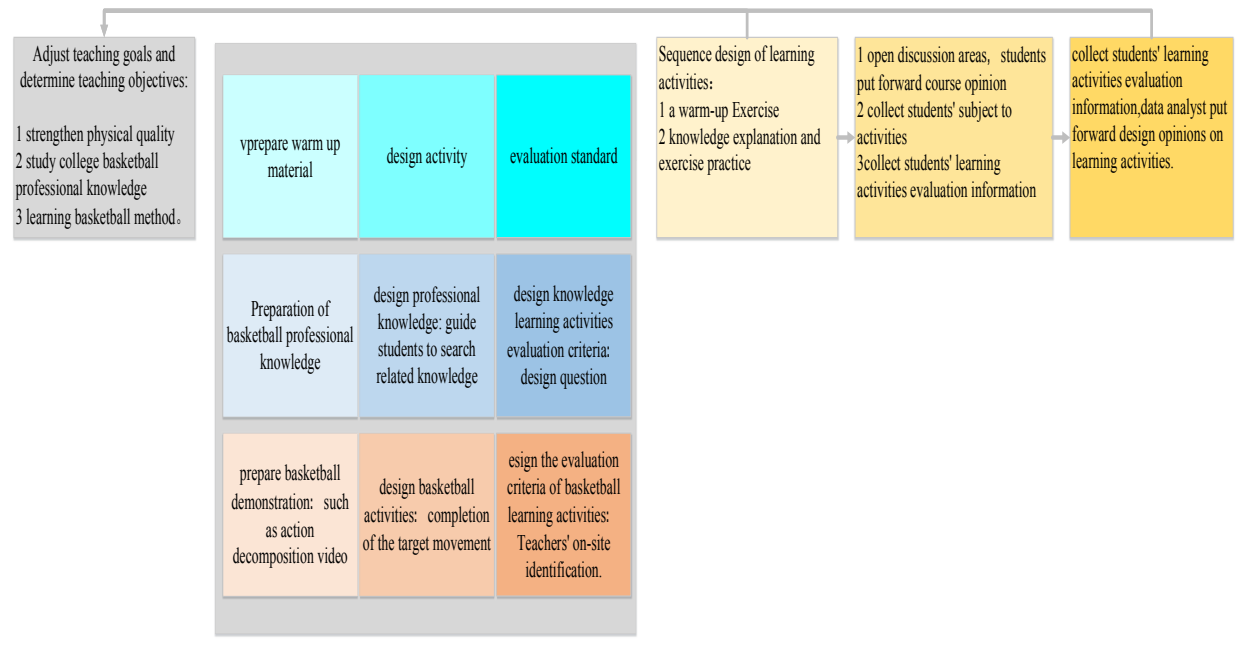

Fig. 4. LAMS-based College Basketball teaching program

In the LAMS-based college basketball teaching program, learning activities are the center. Learning activity design is confirmed through a series of analyses. Then, learning activities are connected in series for the formation of an appropriate learning activity sequence based on course experience. Through information recording function of LASM teaching mode, the teaching objective can be adjusted after the analysis of the activity completion information, completion evaluation, and students' opinions, thus influencing learning activity design. The learning activities are adjusted to reach the better teaching effect.

LAMS-based college basketball teaching mode construction. Considering the analyzed learning activities and teaching mode, we constructed a LAMS-based college basketball teaching mode diagram according to objectivity principle, scientificity principle, operability principle, and simplicity principle of mode construction, LAMSbased College Basketball teaching mode diagram is as shown in Fig.5.

As shown in Figs.2-5, LAMS-based college basketball teaching mode mainly includes two parts, namely, learning activities and learning resources and tools. Learning activities mainly involve teaching objective, learning activity creation, learning activity information collection, information analysis, and activity improvement. Based on the teaching theory centered on learning activities, the teaching mode is divided into learning activities, learning resources, and tools. Learning resources and tools are generally set to make learning activities proceed smoothly. Learning resources and tools are used in the learning activities, and learning activities are adjusted through the tools. 


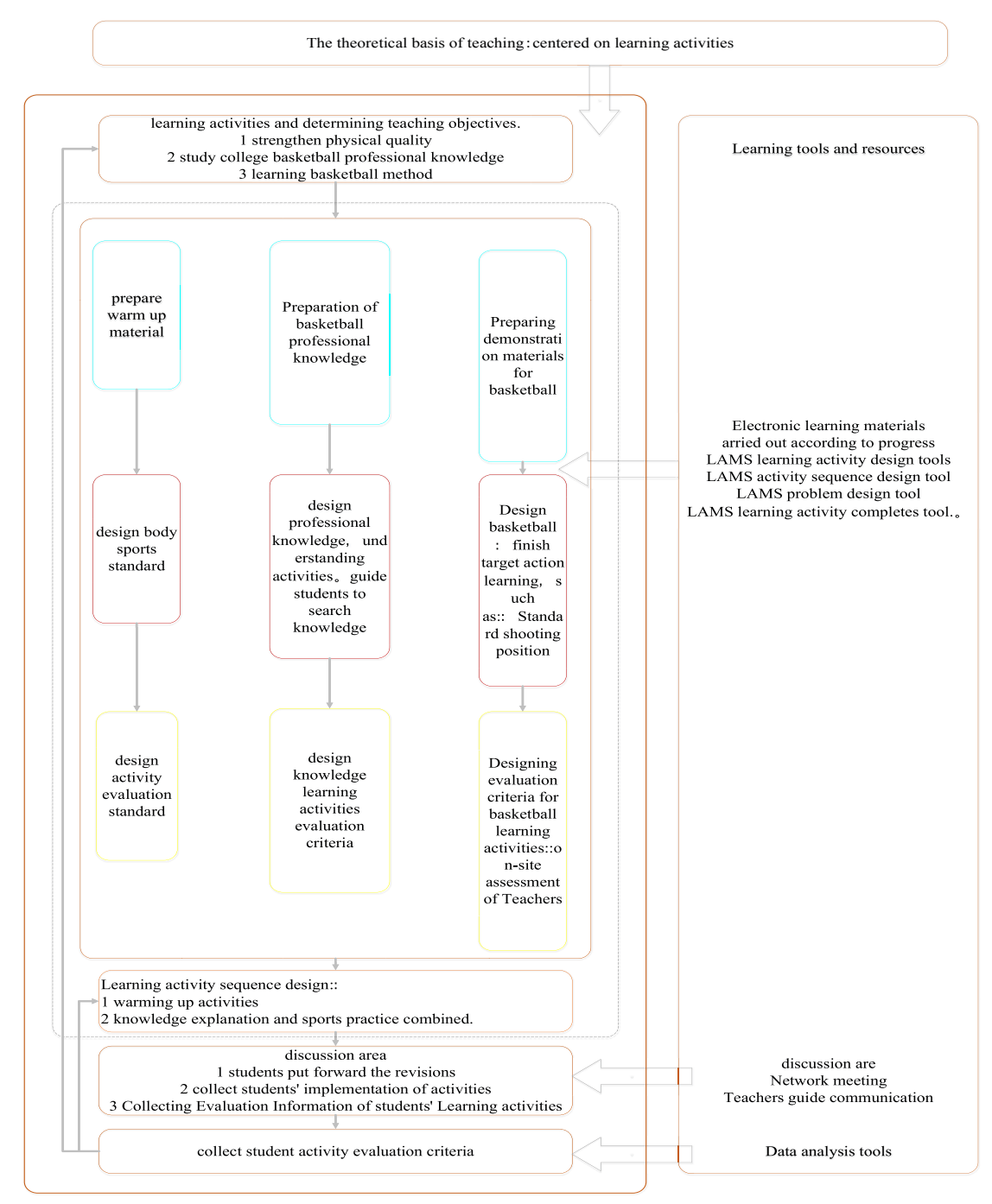

Fig. 5. LAMS-based College Basketball teaching mode diagram

First, the teaching objective is confirmed according to learning activities. In accordance with the three aspects of teaching objective (enhance physical quality, learn professional knowledge of college basketball, and learn movement methods of college basketball), three types of learning activities are created, including warm-up learning activity, professional knowledge understanding activity and basketball activity. On the basis of teacher's rich prior teaching experience, initial learning activity sequence design is conducted for these learning activities. By using learning resources and tools, students and the teacher completed learning activities according to the learning activity sequence. LAMS teaching mode can support nonsynchronous progress of students. Students learn by taking the activity as the unit, and can have their own 
learning progress. This gets rid of the problem that the whole class must keep synchronous, and thus the learning objective cannot be completed or the time is wasted. The LAMS teaching mode allows information gathering through discussion zone, learning progress, and learning activity evaluation. After information analysis, learning activity sequence is adjusted, or influencing learning activity creation by adjusts the teaching objective. Thus, a student can complete a course through learning activities.

\section{$4 \quad$ Teaching example and teaching effect}

\subsection{Teaching example}

Research object. Two classes taking College Basketball in the first semester of 2017 were selected as research object. Each class has 34 students. We selected a class as a control group for traditional teaching. The other classes, as the experimental groups, were taught with the LAMS teaching mode.

Teaching environment. Given that the course is a sports course, the normal place of class is the outdoor basketball court, which presents some obstacles for the LAMS teaching mode. Thus, we used the computer room for the teaching example and conducted the course practice by combining outdoor sports course and indoor theory course. The duration of the course was 13 weeks and 3 hours per week. We applied the form of every two outdoor lessons and one indoor lesson to meet the need of amount of exercise, enhance theoretical knowledge learning, and guide correct exercise.

Learning activity design analysis. The main teaching objective of applying the LAMS teaching mode in college basketball teaching is to guide students to learn professional basketball knowledge systematically and effectively supplement pure exercise training. The learning task design must focus on this teaching objective. We divided learning contents into a series of knowledge point groups according to the teaching objective, as shown in Fig.6.

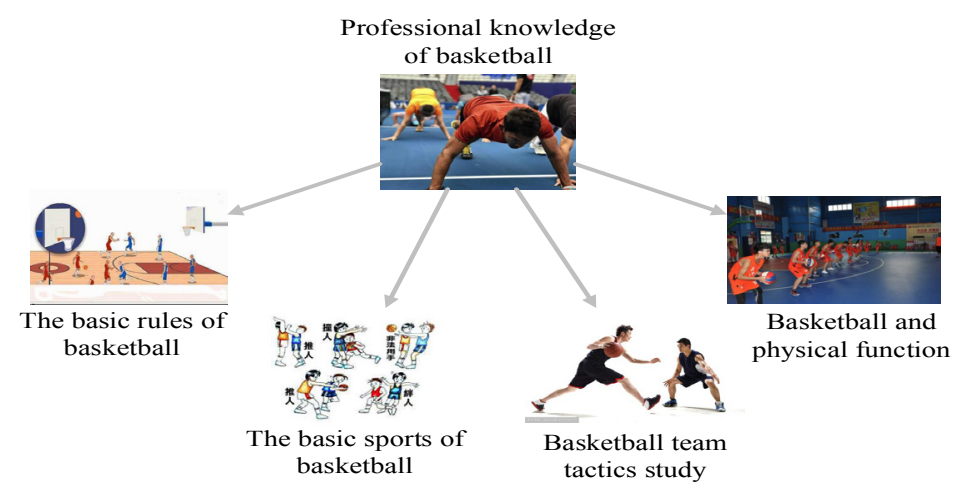

Fig. 6. Division of "systematic professional basketball knowledge" learning contents into knowledge point groups 
Learning mode and method. Course learning is divided into two parts, namely, indoor and outdoor lessons. The outdoor lesson is an exercise course, and it also serves as the test course of indoor theory learning. In the indoor lesson, learners systematically learn professional basketball knowledge through learning activities. The students gradually completes the process by contacting theoretical knowledge to remembering it and through teacher's course teaching, face-to-face communication, teaching material use, and discussion zone use. In the outdoor course, we designed warm-up activities and basketball activities to ensure the amount of exercise. Through emphasizing theory course again, we guided the learners to systematically learn college basketball course. In this process, learners refer to the materials on the LAMS teaching mode to standardize their actions. The face-to-face guidance of teachers ensures exercise standard and course effect.

We designed learning activity sequence of LAMS teaching mode to explain the above process in detail (Table 1). Meanwhile, learning activity sequence was constructed in the LAMS teaching mode, as shown in Figs.7-9.

Table 1. Practical activity design of LAMS teaching mode

\begin{tabular}{|c|c|c|}
\hline $\begin{array}{l}\text { Main teaching } \\
\text { process }\end{array}$ & Activity tool & Activity content \\
\hline Learning description & Noticeboard & Introduce the teaching objective, main activities and tasks \\
\hline \multirow{2}{*}{$\begin{array}{l}\text { Early learning effect } \\
\text { evaluation }\end{array}$} & Assessment & Evaluate learning effect of basic basketball rules \\
\hline & Forum & Discuss basketball rule formulation standards \\
\hline \multirow{4}{*}{ New content learning } & Noticeboard & View teaching materials; the teacher explains systematically \\
\hline & Forum & $\begin{array}{l}\text { Learners publish their opinions in the discussion zone and put } \\
\text { forward questions }\end{array}$ \\
\hline & Noticeboard & $\begin{array}{l}\text { The teacher explains some problems according to the discussion } \\
\text { zone }\end{array}$ \\
\hline & $\begin{array}{l}\text { Resources \& } \\
\quad \text { Forum }\end{array}$ & $\begin{array}{l}\text { Learners enhance understanding through resource collection and } \\
\text { upload new information on the discussion zone }\end{array}$ \\
\hline $\begin{array}{l}\text { Existing knowledge } \\
\text { investigation }\end{array}$ & Q\&A & $\begin{array}{l}\text { Learners review learned knowledge through answering ques- } \\
\text { tions and deepen impression through mutual enlightenment }\end{array}$ \\
\hline $\begin{array}{l}\text { Test and enhance- } \\
\text { ment }\end{array}$ & Outdoor course & $\begin{array}{l}\text { Learners test theory learning in outdoor basketball course and } \\
\text { practice normative movements }\end{array}$ \\
\hline Evaluation & Survey & Learners evaluate the teaching practice \\
\hline Learning effect test & Outdoor course & $\begin{array}{l}\text { The teacher evaluates the teaching effect through assessing } \\
\text { learners' movement standard, strength training degree and skill } \\
\text { mastery }\end{array}$ \\
\hline
\end{tabular}




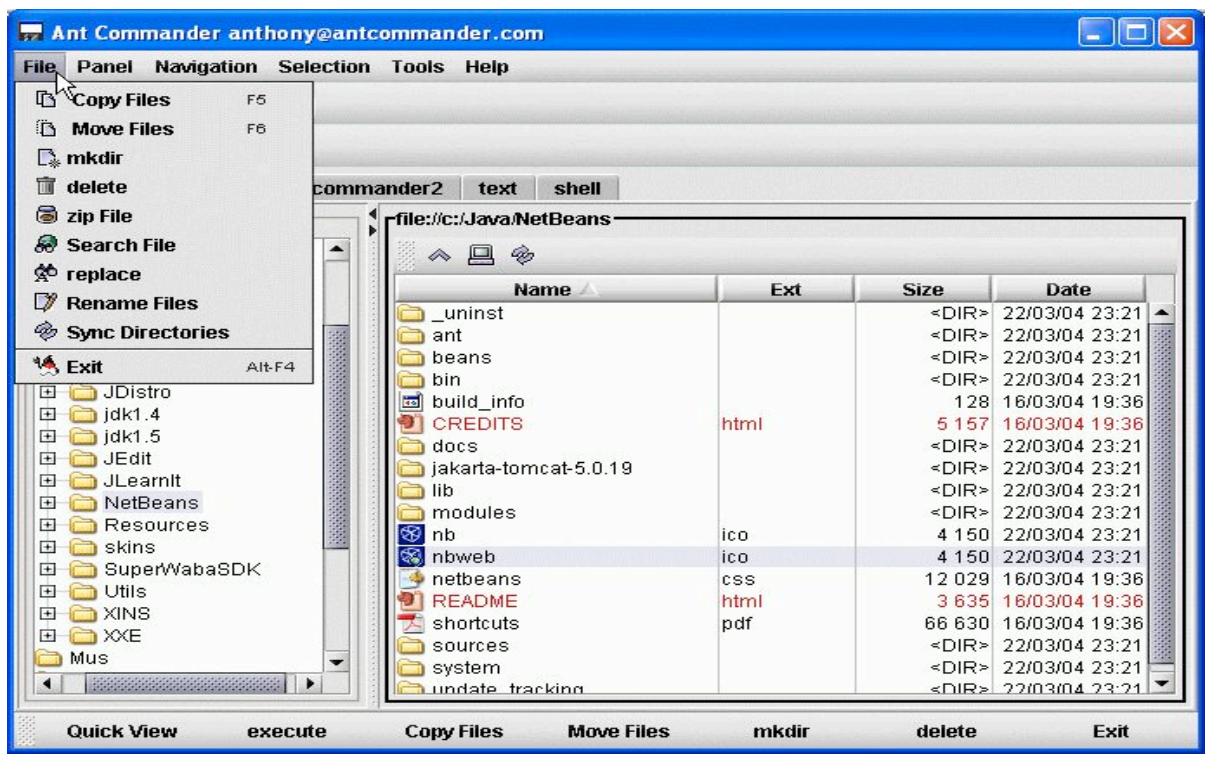

Fig. 7. Learning activity sequence 1 of College Basketball based on LAMS teaching mode

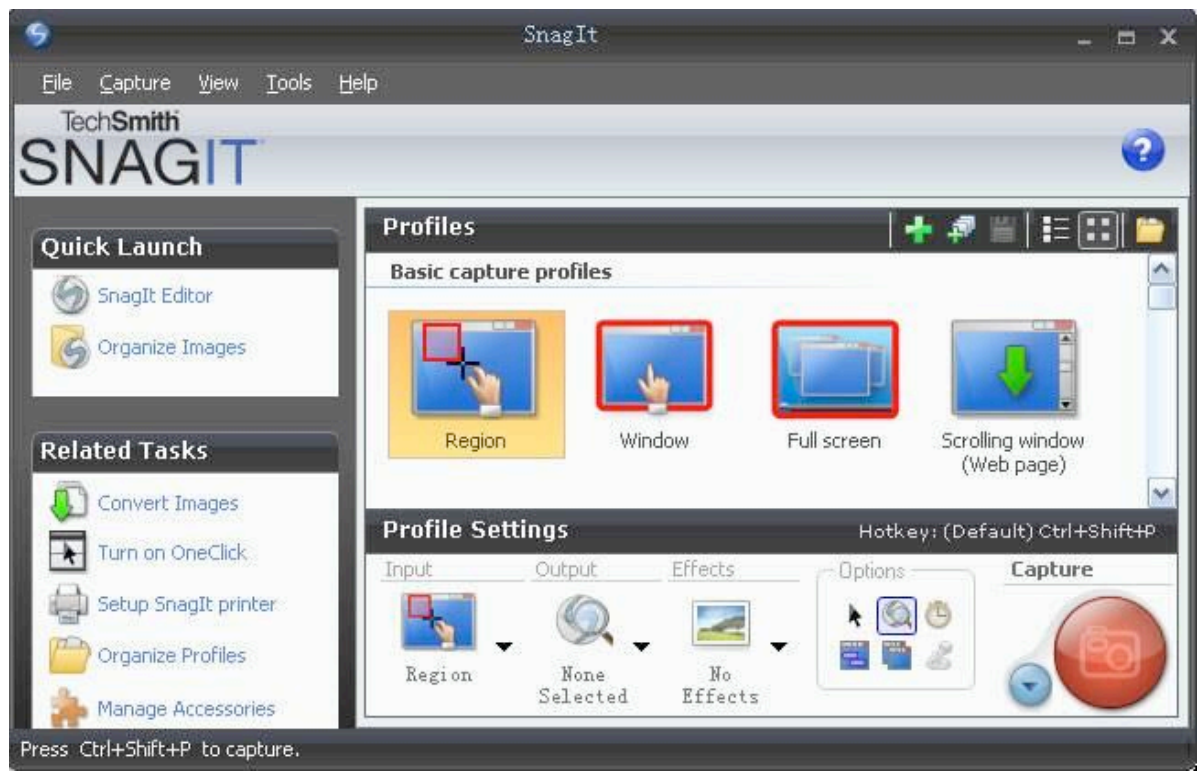

Fig. 8. Learning activity sequence 2 of College Basketball based on LAMS teaching mode 


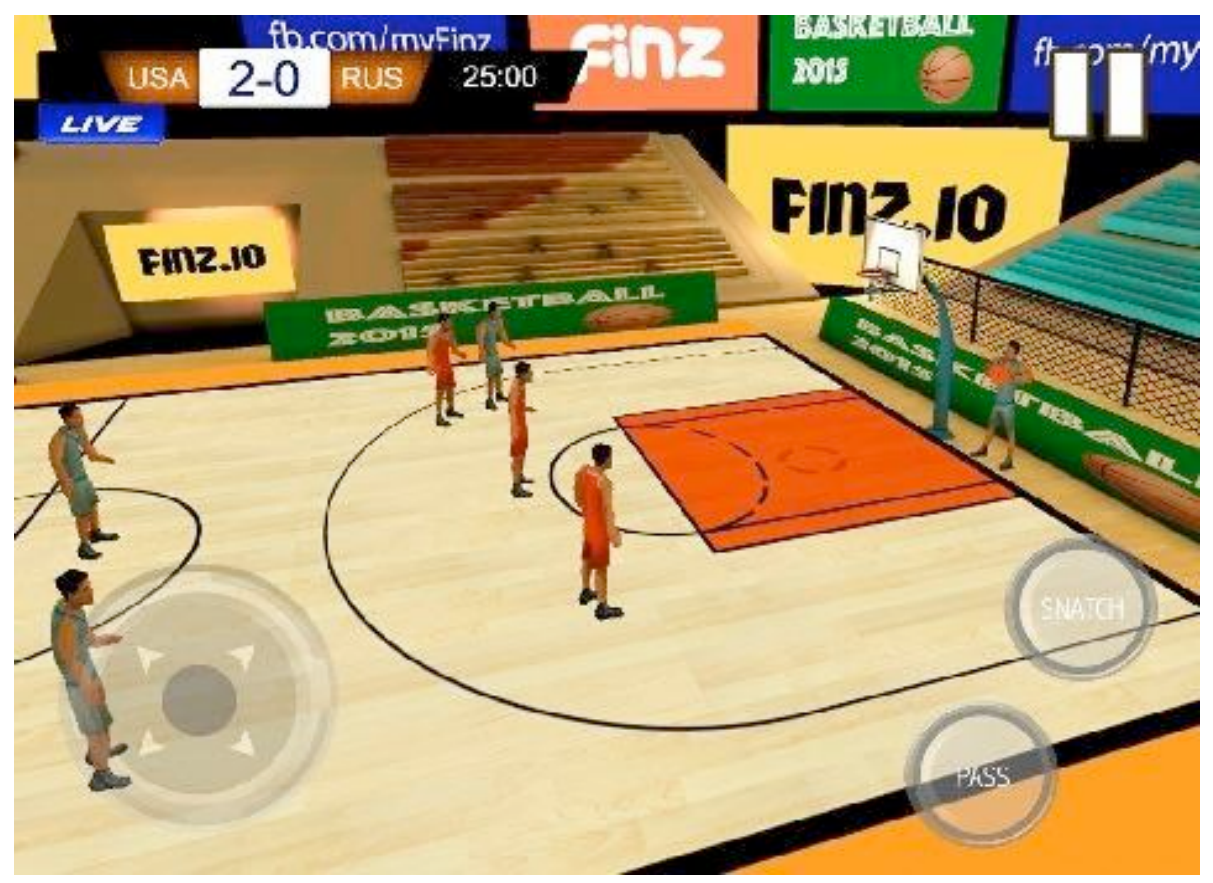

Fig. 9. Learning activity sequence 3 of College Basketball based on LAMS teaching mode

\subsection{Teaching effect}

In the practical activity design, the teaching example was evaluated from two aspects. On the one hand, from the perspective of learners, learners self-evaluated their harvest gained from the course. On the other hand, from the perspective of the teacher, whether the teaching example reached the teaching objective? Whether physical strength was enhanced? Whether basketball skills were mastered?

Basing on the assessment from the first aspect, we investigated the harvest degree gained from College Basketball through the questionnaire. The answers to the questionnaire were divided into four dimensions, namely, no gain, some gains, large gains, and great gains. The questionnaire covered all students (34) in the experimental class, and 32 effective questionnaires were collected, accounting for $94 \%$ of questionnaires distributed.

As shown in the questionnaire results, only $6.2 \%$ of the learners considered that they gained nothing from the teaching practice, whereast $78.4 \%$ thought they had gained much from the course. Although the questionnaire survey adopted a nonquantitative question form, most learners approved the teaching effect of the LAMS-based college basketball teaching mode.

For the evaluation in the second aspect, two teachers scored learners' performance. The teachers did not know which group the students belonged to. Under this condition, the two teachers scored all research objects (68) in both groups. The mean value of the scores was considered the score of each learner for the quantitative evaluation 
of the teaching effect. In Table 2, the number of learners with the score less than 60 in the experimental group decreases, and the number of learners with the score between 60 and 69 declines as well. These data indicates that the learners in the score section can improve their performance in the course through the LAMS teaching mode. Among the learners with the score above 80, experimental group is doubles as much as the control class, compared with the control group. Thus, the LAMS teaching mode is not only effective in teaching learners in the low score section but also plays a role in the learning of individuals in the high score section. Moreover, an obvious difference in core distribution was observed between the groups. The scores of the experimental group were mainly distributed between 70 and 79 , whereas the sores of the control group were mainly distributed between 60 and 69 . The performance of the experimental group was superior to that of the control group.

Table 2. Teacher's scoring for traditional teaching class and LAMS teaching class

\begin{tabular}{|l|c|c|c|c|c|c|c|}
\hline \multirow{2}{*}{ Group } & \multirow{2}{*}{ No. } & \multirow{2}{*}{$\begin{array}{c}\text { Average } \\
\text { scores }\end{array}$} & \multicolumn{6}{|c|}{ No. of every scores } \\
\cline { 4 - 9 } & & & Below 60 & $\mathbf{6 0 - 6 9}$ & $\mathbf{7 0 - 7 9}$ & $\mathbf{8 0 - 8 9}$ & $\begin{array}{c}\text { More than } \\
\mathbf{9 0}\end{array}$ \\
\hline Control group & 34 & 72.5 & 4 & 13 & 10 & 6 & 1 \\
\hline Experimental group & 34 & 81 & 2 & 6 & 9 & 13 & 4 \\
\hline
\end{tabular}

\section{Conclusions}

The teaching theory centered on teaching activities has become a theory and has been widely applied in online teaching. LAMS-based teaching modes are expected to improve online learning experience for learners. College basketball LAMS teaching mode was constructed, and learning activities were considered the center. First, relevant domestic and overseas research in this field was analyzed. On this basis, the research innovation was proposed. Second, the theoretical basis of the LAMS teaching mode was expounded on the basis of the activity theory and educational mode. Finally, the construction process of the LAMS teaching mode based on learning activity design was described. The process involves the teaching mode component, teaching activity object analysis, and teaching program design. These elements were synthesized for the formulation of a LAMS teaching mode. After the teaching mode was constructed, learning activity sequence was practically created by the LAMS teaching mode and applied in practical teaching process. The effect of this teaching mode was assessed in the form of questionnaire survey, and the following conclusions were drawn:

1. The LAMS teaching mode should be introduced in college basketball teaching. Classroom teaching and distance teaching should be combined in a manner that students grasp the LAMS teaching mode, experience teaching-learning relation in distance education, and understand relevant distance teaching and knowledge. This approach enables the students to engage in relevant PE teaching work after their graduation. 
2. After theory course teaching, course practice should be designed. Students should independently design teaching courseware required by the LAMS teaching mode according to the guidance of relevant teaching design theory. On the one hand, the students can develop their teaching process design ability. On the other hand, they can experience and think the teaching design concept centered on teaching activities.

3. The course practice link in this study has motivated students' interest in the learning theory course and promoted the development of their advanced thinking ability. Moreover, it partly resolves learning difficulties and improves learning results. The proposed teaching method can help students enhance their comprehension and meet colleges' comprehensive ability requirements for PE graduates.

\section{Acknowledgment}

This work was supported by Youth Fund of Humanities and Social Sciences Research Project of Education Ministry (14YJC890022) and Social Science Planning Research Project of Shandong Province (13CTYJ04).

\section{$7 \quad$ References}

[1] Sato, T., Haegele, J.A. Physical educators' engagement in online adapted physical education graduate professional development. Professional Development in Education, 2018, vol. 44(2), pp. 272-286. https://doi.org/10.1080/19415257.2017.1288651

[2] Peng, Y.F., Zhu, R. Decline and $\square$ evival of Game Spirit in Physical Education. Journal of Beijing Sport University, 2016, vol. 39(3), pp. 100-105.

[3] Sun, J.W. Study on the countermeasures of college physical education reform in the new situation. Contemporary Sports Technology, 2016, vol. 6(18), pp. 1-2.

[4] Chen, X.P., Jia, J. Applicaoion of the Internet in the Physical Education in University. Journal of Military Physical Education and Sports, 2001, vol. 20(4), pp. 82-85.

[5] Healy, S., Judge, J., Strehli, L., et al. A practical guide to the development of an online course in adapted physical education. Palaestra, 2017, vol. 31(20), pp. 48-54.

[6] Hollis, J.L., Williams, A.J., Sutherland, R., et al. A systematic review and meta-analysis of moderate-to-vigorous physical activity levels in elementary school physical education lessons. Preventive Medicine, 2016, vol. 86(1), pp. 34-54. https://doi.org/10.1016/j.ypm ed.2015.11.018

[7] Yang, K.C. One Paradigm and Two Trends for Instructional Design Theory. China Educational Technology, 2004, vol. 3, pp. 15-19.

[8] Chan, L.K., Jr, G.F., Fky, W., et al. Implementation of an interprofessional team-based learning program involving seven undergraduate health and social care programs from two universities, and students' evaluation of their readiness for interprofessional learning. Bmc Medical Education, 2017, vol. 17(1), pp. 1-12. https://doi.org/10.1186/s12909-017-1046-5

[9] Dalziel B, Dalziel B. Designing LAMS templates for medical education. Proceedings of the 2nd International LAMS Conference, 2007, pp. 43-49. 


\section{Authors}

Feng Sheng is a lecturer in the Qufu Normal University, Qufu 273165, China (3352165615@qq.com).

Shaozeng Sheng is a lecturer in the Qufu Normal University, Qufu 273165, China (3352165615@qq.com).

Article submitted 16 April 2018. Resubmitted 25 June 2018. Final acceptance 23 July 2018. Final version published as submitted by the authors. 